\title{
Nutrition and AIDS in the Caribbean: Looking beyond survival
}

\author{
Nicole Simpson ${ }^{1}$, Fitzroy J. Henry*2 \\ ${ }^{1}$ Department of Dietetics, Kingston Public Hospital, Jamaica \\ ${ }^{2}$ College of Health Sciences, University of Technology, Jamaica
}

Received: October 16, 2016

Accepted: February 21, $2017 \quad$ Online Published: March 1, 2017

DOI: $10.5430 /$ jer.v3n2p1

URL: https://doi.org/10.5430/jer.v3n2p1

\begin{abstract}
This study randomly selected HIV positive patients attending the largest hospital in Jamaica and analyzed their health, nutritional and socio-demographic profiles. Adherence to highly active antiretroviral therapy was good overall and patients reported to have good appetite and most consumed at least 1-2 meals daily with snacks despite financial challenges. The nutritional status findings largely mirrored the trends in the general population towards increasingly overweight and obesity. The results also showed low rates of weight loss and under-nutrition but relatively high rates of non-communicable diseases. The contrasting recommendations on energy intake for persons living with AIDS and those obese create a potential nutritional dilemma for treatment and rehabilitation. This study concludes that priority attention must be directed towards designing a comprehensive nutrition program for AIDS survivors in the Caribbean.
\end{abstract}

Key Words: AIDS, Obesity, Nutrition, Non-communicable diseases, Caribbean

\section{INTRODUCTION}

The importance of nutrition in the management of AIDS in the Caribbean has been previously highlighted. ${ }^{[1]}$ At that time the HIV incidence and fatality rates were high and the devastating effects of AIDS on nutritional status were a major concern. It was recognized that nutrition can delay the progression of AIDS, but with comprehensive nutrition therapy not being a major part of management efforts it raised the question whether an opportunity was being lost. ${ }^{[1]}$ More recently the global incidence of HIV infection has declined by $35 \%$ since 2000 , and new cases of HIV infection among children has also fallen by $58 \% .{ }^{[2]}$

Today, highly active antiretroviral therapy (HAART) is available for free to HIV positive individuals in most Caribbean countries and numerous prevention programs have developed targeting at-risk groups and vulnerable communities. ${ }^{[3,4]}$ With fatality declining the question now becomes what should be the optimal nutritional management of AIDS survivors?

Despite the declines in incidence and deaths from AIDS the prevalence of HIV-infection in the Caribbean is still unacceptably high. Nutritional intake is still often overlooked although the relation between nutrition and immune function is well established. ${ }^{[5]}$ The essential nutrients can be easily acquired in the appropriate amounts daily by consuming foods from each of the Caribbean foods groups. In 2003 Knox and colleagues noted that deficiencies in serum Vitamin A, Vitamin B12, selenium and zinc have been associated with

\footnotetext{
*Correspondence: Fitzroy J. Henry, Professor; Email: Fitzroy.Henry@utech.edu.jm; Address: College of Health Sciences, University of Technology, 237 Old Hope Road Kingston, Jamaica.
} 
progression of HIV infection. ${ }^{[6]}$ Despite the recent success of HAART, malnutrition due to inadequate food intake remains a serious problem for persons with advanced HIV disease. ${ }^{[7]}$

It was therefore critical to assess the nutritional outcome of individuals infected with HIV whose nutritional management is carefully monitored. This study conducted such as assessment at the main hospital in Jamaica - a tertiary care setting, where patients are usually presented with severe wasting. This wasting results from advanced progression of their HIVinfection; inadequate dietary intake due to food and nutrition knowledge deficit, further exacerbated by varying socioeconomic and cultural factors. The aim was to determine how nutrition therapy can be optimized as part of a comprehensive approach to AIDS treatment and rehabilitation.

\section{MethodS}

The study was approved by the ethics committees of the University of Technology, Jamaica and the Ministry of Health, Jamaica. Every third randomly selected HIV-positive patient attending and registered at the main hospital in Kingston was invited to participate in the study over a 7-week period. All ethical concerns were satisfactorily addressed before verbal and written consent was obtained. To ensure confidentiality initials were used on the consent form. Interviews were conducted in an area remote from the location of the clinic area and study information was stored in a password-protected data base.

Each study participant's medical record was carefully reviewed to confirm HIV infection and clinical stage. Information collected included their medical history, relevant laboratory data, changes in body weight during their clinic attendance course, prescribed medications including ARV, the referral record for integrated clinical services with emphasis on nutrition intervention. Patients over 21 years were included. Patients to be excluded were those with a medical history of dementia or other cognitive deficits; a history of mental illness with delusion or psychosis because of impediments in the ability to recall information; disability which prohibited independence in walking or self-care (e.g., paralysis secondary to spinal cord injury or stroke with hemiparesis). With the higher rate of muscular atrophy that has been observed in patients with paralysis or dependence on a wheelchair for ambulation, the plan to exclude them from this study was based on preventing the occurrence of potentially confounding factors, such as an over-estimation in the prevalence of underweight. During selection we found no patient with such disabilities to be excluded. All study participants were interviewed with a structured questionnaire which included a food frequency table. Seventy six food items from various food groups were included in the food frequency table. Each study participant was screened with the well-validated Mini Nutritional Assessment (MNA) tool $^{[8]}$ to identify those who were at risk for malnutrition.

Student's $t$-test and correlation analyses were used to test statistical significance among continuous variables such as age, weight, BMI, MNA scores and CD4 counts. Differences in categorical variables such as physical activity level, visceral protein status and clinical stage of HIV were analyzed by the chi-square test.

\section{RESULTS}

The sample consisted of forty-four adults: 24 females and 20 males. The age range was from 21 to 77 years with a mean of 45.8 years. Most $(72.8 \%)$ of the patients live within 5 miles of the Kingston Public Hospital where the study was done. The cost of access to services was therefore small.

Compliance with medication, specifically HAART, is noted at $45.2 \%$ as indicated by daily or consistent use as prescribed. The remaining patients cite poor tolerance of the medication (16.7\%); fasting with ingestion of herbs (12.5\%); and not remembering to take their medication $(20.8 \%)$ as the most common reasons for non-compliance or inconsistent use of their medication. Importantly, $12.5 \%$ do not take their medications as they believe the HAART is no longer necessary.

The period since HIV diagnosis correlated positively with the CD4+ count $(p=.001)$. In evaluating the prevalence and severity of immunosuppression, $35 \%$ of the females have no significant immunosuppression (CD4+ count of 500 or more), compared to $17.6 \%$ males with no significant immunosuppression, but $35.3 \%$ of the male respondents had mild immunosuppression (CD4+ count between 350 and $499)$ compared to $15 \%$ of females. Many males $(47.1 \%)$ had advanced to severe immunosuppression (CD4 count less than $350)$ compared to $50 \%$ of females.

All patients reported receiving some type of counseling consistent with their HIV therapy. Counseling was for HIV medical treatment $(52.4 \%) ; 10.7 \%$ for emotional support; $3.6 \%$ to address mental health concerns; $7.1 \%$ for behavior change; and $26.2 \%$ for diet and nutrition. Counseling was provided by the medical officer $(41.6 \%)$, nurse $(20.8 \%)$, dietitian (17.8\%), pharmacist $(3.0 \%)$, adherence councilor $(4.0 \%)$, social worker $(2.0 \%)$, and clergyman $(1.0 \%)$.

Financial support is critical to the nutritional support of HIV patients yet there was an unemployment rate of $45.4 \%$ with women having a higher rate of $54.2 \%$. Of the unemployed, alternate sources of financial support came from their spouse or partner (20.7\%); parent (17.2\%); siblings $(10.3 \%)$; friend (13.8\%); adult child (13.8\%); extended family mem- 
ber $(6.9 \%)$, public assistance $(10.3 \%)$ and $6.9 \%$ did not have any regular source of financial assistance. For the employed, the estimated weekly income in Jamaican dollars was $\$ 3,000$ to $\$ 6,000$ (37.5\%); $\$ 6,100$ to $9,000(25 \%) ; \$ 9,100$ to $\$ 12,000$ $(25 \%)$ and above $\$ 12,000(12.5 \%)$.

Twenty seven patients $(61.4 \%)$ indicated they needed financial assistance to consistently meet their nutritional needs. Most $(72.8 \%)$ of the patients consumed a general unrestricted diet. Of the remaining 12 on a restricted diet: 5 were on lowsalt; 4 on low-sugar; one on low-fat; one on a renal diet and one avoided tinned foods.

Many (36.4\%) patients regularly ate 3 meals daily; $22.7 \%$ ate 2 to 3 meals often and 40.9 ate 1-2 meals regularly. Among the 18 who ate 1-2 meals, fourteen consumed additional snacks. Consumption of dietary supplements was reported by $65.9 \%$ as a routine part of their diet. Vitamins (B-complex), herbs or herbal extracts and omega-3 in the form of fish oil are the most frequently consumed dietary supplements. Only $16.9 \%$ reported use of alternative medical therapies such as moringa (Moringa oleifera).

Most respondents $(81.8 \%)$ reported having a good appetite and $13.6 \%$ indicated their appetite is fair. Only $4.6 \%$ reported having a poor appetite. Rice was the most frequently consumed staple followed by boiled green banana. Poultry, meat, fish and eggs were common in the diet. Milk was not consumed by $54.6 \%$ while legumes such as red peas and gungo peas were frequently used. Fresh fruits and vegetables were not consumed daily. Tomato and cabbage were the most preferred. Canned fish is consumed two to three times weekly by $34.1 \%$ of respondents, and canned meat was consumed by $22.8 \%$ one to three times weekly. Carbonated beverages were drunk at least one time each day by $13.6 \%$ of the respondents, while fruit-flavored beverages were consumed daily by $29.5 \%$. Bagged "juice" (sugared-water with flavoring in a plastic bag) was drunk by $13.6 \%$ of respondents about two to three times weekly and up to six times weekly by $11.4 \%$ of them. In addition to the sweetened beverages, $31.8 \%$ of respondents consumed refined sugar one time each day and $36.4 \%$ used this added sugar two to three times each week. Condensed milk was consumed by $13.6 \%$ of respondents two to three times each week. Margarine made from vegetable oils was the most common fat consumed $-22.7 \%$ used it each day while $11.4 \%$ used margarine four to six times each week.

Alcohol drinking was done occasionally by $33.3 \%$ of females and $45.0 \%$ of males. Smokers were $33.3 \%$ female and $60 \%$ male. Of these, marijuana smoking was regular in men $(58.3 \%)$ and $50 \%$ among women.
Overall, $41 \%$ of patients were overweight or obese with $47.7 \%$ classified within normal weight parameters. Table 1 shows that overweight or obesity in females was $54.2 \%$ with average BMI of 26.5 compared to $25 \%$ in males with an average BMI of 22.8. Most (70\%) males were involved in moderate to heavy physical activity whereas only $29.2 \%$ for females were so engaged. For underweight, however, males had a rate of $20 \%$ whereas for females it was $4.2 \%$. Using the malnutrition risk scores, $66.7 \%$ of females were normal compared with $55 \%$ in males. The risk of malnutrition in males $65.0 \%$ compared with $35.0 \%$ for the females.

Table 1. Gender comparisons of HIV positive patients by $\mathrm{BMI}$ and malnutrition risk

\begin{tabular}{lll}
\hline Indicators & $\begin{array}{l}\text { Males }(\mathbf{n}=\mathbf{2 0}) \\
\text { \% }\end{array}$ & $\begin{array}{l}\text { Females }(\mathbf{n}=\mathbf{2 4}) \\
\text { \% }\end{array}$ \\
\hline Malnutrition Risk (MNA) & & \\
Normal Nutritional status & 35.0 & 66.7 \\
Risk for Malnutrition & 65.0 & 25.0 \\
Malnourished & 0 & 8.3 \\
Weight Classification (BMI) & & \\
Underweight (<18.5 ) & 20.0 & 4.2 \\
Normal (18.5-24.9) & 55.0 & 41.7 \\
Overweight (25-30) & 10.0 & 29.2 \\
Obese (> 30) & 15.0 & 25.0 \\
Physical Activity & & \\
Sedentary & 10.0 & 20.8 \\
Light & 20.0 & 50.0 \\
Moderate & 50.0 & 29.2 \\
Heavy & 20.0 & 0 \\
BMI (kg/m $\left.{ }^{2}\right)$ Mean (SD) & $22.8(6.1)$ & $26.5(5.1)$ \\
\hline
\end{tabular}

With the exception of the mean hemoglobin all laboratory indicators appeared to be within normal parameters for both genders. Satisfactory visceral protein status (albumin) was noted overall for males at $70.0 \%$ and females at $71.4 \%$, with male respondents having a higher proportion (30\%) for depletion of serum albumin compared to the females. Total protein status within the normal range was similar between both genders at $60 \%$ for males and $57.1 \%$ for females. However, $14.3 \%$ of females have total protein stores below the reference range, but there were no males observed with this deficiency. For hyperproteinaemia, $40 \%$ of the males and $28.6 \%$ of females were noted.

Patients with a medical history of chronic non-communicable diseases are shown in Figure 1. Hypertension (28.4\%) is the most common chronic health concern and diabetes $(10.4 \%)$ dyslipidemia (6.0\%) and chronic kidney disease $(6.0 \%)$ had the next highest rates. A history of trauma, including physical assault and gunshot wounds, was also noted at a rate of $4.5 \%$, and symptomatic HIV infection - though not a non- 
communicable disease - but relevant in assessing nutritional status was noted at a rate of $34.3 \%$.

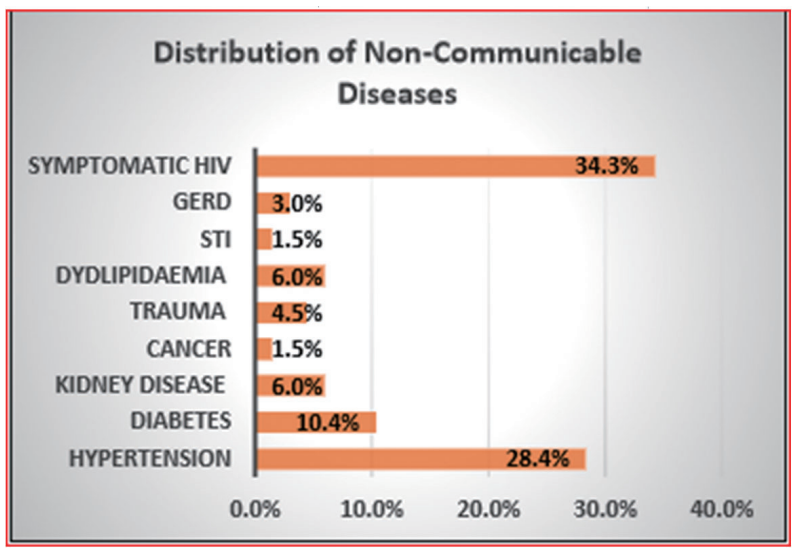

Figure 1. Distribution of non-communicable Diseases among HIV positive patients

\section{Discussion}

A key determinant of the survival rates of persons infected with HIV is the level of compliance with medications. This study showed a moderately high compliance with HAART and with the available nutrition support there was negligible wasting observed. Less than $12 \%$ were underweight or had evidence of chronic energy deficiency. In addition there was also low incidence of illness-related factors such as diarrhea, vomiting, and oropharyngeal candidiasis which can negatively influence dietary intake.

There was no statistically significant relationship between the CD4+ count, weight and BMI in this cohort. This, however, does not diminish the potential for the use of the CD4+ count as a determinant of nutritional status as there was a positive and significant relationship noted between the CD4+ count and malnutrition risk, as observed elsewhere. ${ }^{[9]}$

This study did not indicate that the consumption of alcohol or marijuana are factors for concern as related to the dietary intake and nutritional status. Although it is recommended ${ }^{[10,11]}$ that three moderately portioned meals should be consumed each day consisting of foods from all food groups, it was noted in this study that over forty percent of the respondents consumed only one to two meals each day along with only one snack. This group of patients may not be consuming adequate calories or a nutritionally balanced diet and hence may cause a decline in body weight with an increasing disposition for malnutrition. It was noted, however, that staples such as rice and protein-rich foods such as chicken and legumes were consumed regularly, therefore energy-protein malnutrition was not a concern. The consumption of fresh fruits and vegetables each day was significantly low, but not remarkable as compared to the findings reported in the Jamaica
Health and Lifestyle Survey. ${ }^{[12]}$ This low frequency of fruit and vegetable consumption was therefore consistent with that of the general Jamaican population. The study showed that over $80 \%$ of patients were either normal or overweight. Obesity rates were $20 \%$ in this study which is higher than the $8 \%$ found in hospital patients with HIV in St. Vincent and the Grenadines in 2008. ${ }^{[13]}$ The high rate of obesity among HIV infected patients has been described as the latest epidemic. ${ }^{[14]}$ As high-sodium foods such as canned meat and canned fish are consumed regularly in this sample, compounded by the consistently low consumption of fruits and vegetables the concern now moves to the high proportion of HIV positive patients with hypertension, diabetes and other non-communicable diseases. These patients, however, are not on a therapeutic diet to manage their chronic illness. The frequent consumption of sweetened beverages and refined sugar was noted and in combination with the low rates of exercise, this may exacerbate overweight and obesity - risk factors for diabetes and other chronic non-communicable diseases.

People living with HIV are sometimes offered dietary supplements such as vitamins for immune health; iron tablets to correct and prevent anemia which is quite common; and liquid high calorie-high protein beverages to prevent HIVassociated weight loss. In this study, over $65 \%$ of the respondents were supplementing their diets with vitamin and mineral supplements. There was a mild depletion in the mean hemoglobin of the female respondents, but in general and with adequate consumption of foods from animals, iron-deficiency related anemia was not a concern.

Employment status and earnings of patients may determine how much and what types of food is consumed, and ultimately affect their nutritional status. Patients were generally from a low socioeconomic background with a high proportion of unemployment. Less than forty-two percent of employed patients earned less than the national minimum wage. Over two-thirds of the patients indicated they need assistance to consistently acquire food. Despite the unfavorable unemployment rate and financial challenges, the majority of unemployed respondents received financial and other social support from their intimate partner or spouse, and also from an immediate or extended family member, which perhaps circumvented the malnutrition risk.

In general, patients survived the various challenges presented to them daily as evidenced by the favorable proportion with a high rating for life-satisfaction. Some of the respondents stated that their situation could have been even more dire if they were not taking their medications or making efforts to take care of their bodies. They admitted to experiencing 
daily challenges to care for themselves and their families because of their HIV status and the currently difficult economic climate in Jamaica.

It should be emphasized that this cohort reflects patients who voluntarily sought treatment and care. No doubt many others do not seek and receive the same attention because of distance, cost, stigma, discrimination, among other reasons. This study therefore points to the potential outcomes if regular monitoring and counseling are in place.

\section{Conclusions}

This study of persons living with HIV showed a dietary intake similar to that of the Jamaican populace as determined by the Jamaica Health and Lifestyle Survey ${ }^{[12]}$ Further the proportions for non-communicable disease such as hypertension and diabetes were similar to those reported in that survey. This underscores the need to promote good nutrition, particularly the increased consumption of fruits and vegetables for HIV positive persons.

Significant weight loss as related to HIV-infection was not observed in this study. Respondents reported to have a good appetite and a high compliance rate in taking their antiretroviral medication. However, the imbalance between energy intake and energy expenditure, as evidenced by a high proportion of overweight and obese respondents is a concern taking into consideration the risk for non-communicable diseases. The World Health Organization ${ }^{[10]}$ recommends increased energy intakes between $10 \%$ and $30 \%$ depending on the symptoms in HIV-infected adults. WHO also recommends limitation of energy intake for obese adults. ${ }^{[15]}$ Herein lies a potential dilemma for the nutritional management of obese adults living with HIV.

In the Caribbean the focus needs to shift from solely preventing weight loss in people living with HIV to promoting their optimal good health and well-being as related to the prevention of non-communicable diseases and ensuring their mental health. In addition to monitoring blood pressure, the inclusion of finger-stick testing of blood glucose or urinalysis with a dipstick, should be considered for all patients upon presentation to the clinic to identify those with diabetes mellitus and other chronic diseases associated with overweight and the metabolic syndrome. An interdisciplinary approach is critical not only in meeting the nutritional needs of persons living with HIV but also to address psychosocial issues which can have a negative effect on their overall health. ${ }^{[16]}$ Programs should be directed also to family members and community action groups for additional social support. The core objective in the Caribbean must be to encourage good nutrition and regular exercise as the primary tools for successful treatment of HIV-infection as well as the prevention of non-communicable diseases.

\section{ACKNOWLEDGements}

We thank Kerisha Williams-Chin Loy and Tishera Brown who performed admirably in collating the hospital data. We are also grateful for the support and active cooperation of the participants and their families who were vital to the success of this study.

\section{CONFlicts OF INTEREST Disclosure}

Authors declare that they have no competing interests.

\section{REFERENCES}

[1] Henry FJ. Nutrition in AIDS management: an opportunity being lost. West Indian Medical Journal. 2003; 52(2): 89-90.

[2] UNAIDS. Global Statistics: Fact Sheet. UNAIDS. 2014

[3] Figueroa JP, Duncan J, Byfield L, et al. A comprehensive response to the HIV/AIDS epidemic in Jamaica a review of the past 20 years. West Indian Medical Journal. 2008; 57(6): 562-575.

[4] NHP. National HIV/STI Programme (NHP) \& National Family Planning Board-Sexual Health Agency (NFPB-SHA). Global AIDS Response Report. 2014: 2012-2-13.

[5] Kim JH, Spiegelman D, Rimm E, et al. The correlates of dietary intake among HIV-positive adults. The American Journal of Clinical Nutrition. 2001; 74(6): 852-861.

[6] Knox TA, Zafonte-Sanders M, Fields-Gardner C, et al. Assessment of nutritional status, body composition, and human immunodeficiency virus-associated morphologic changes. Clinical Infectious Diseases. 2003; 36(Supp. 2): S63-S68. PMid:12652373 https: //doi.org/10.1086/367560

Published by Sciedu Press
[7] Lennie TA, Neidig JL, et al. Assessment of hunger and appetite and the relationship to food intake in persons with HIV infection. Journal of the Association of Nurses in AIDS Care. 2001; 12(3): 66-74. https : //doi.org/10.1016/S1055-3290(06)60145-3

[8] Vellas B, Villars H, Abellan G, et al. Overview of the MNA-its history and challenges. The Journal of Nutrition, Health and Aging. 2006; 10(6): 456-465. PMid:17183418

[9] Duggal S, Das Chugh T, Duggal AK, et al. HIV and malnutrition: effects on immune system. Clinical \& Developmental Immunology. 2012; 2012: 1-8. PMid:22242039 https://doi.org/10.1155/ 2012/784740

[10] WHO. Nutritional requirements for persons with HIV/AIDS: Report of Technical consultation. Geneva. 2003.

[11] Nerad J, Romeyn M, Silverman E, et al. General nutrition management in patients infected with human immunodeficiency virus. Clinical Infectious Diseases. 2003; 36(Suppl. 2): S52-S62. PMid:12652372 https ://doi.org/10.1086/367559

[12] Wilks R, Younger N, Tulloch-Reid M, et al. Jamaica health and lifestyle survey 2007-8: Technical report. Epidemiological Research 
Unit UWI. 2008.

[13] Burgin J, Nichols S, Dalrymple N. The nutritional status of clinic attendees living with HIV/AIDS in St. Vincent and the Grenadines. West Indian Medical Journal. 2008; 57(5): 438-443. PMid:19565972

[14] Crum-Cianflone N, Tejidor R, Medina S, et al. Obesity among HIV patients: the latest epidemic. AIDS Patient Care STDS. 2008; 22(12): 925-930. PMid:19072098 https://doi.org/10.1089/apc. 20
08.0082

[15] WHO. Obesity: preventing and managing the global epidemic: Rerport of WHO consultation. Technical Report Series, \#894. Geneva. 2004.

[16] Clarke TR, Gibson RC, Barrow G, et al. Depression among persons attending a HIV/AIDS outpatient clinic in Kingston, Jamaica. West Indian Medical Journal. 2010; 59(4): 369-373. PMid:21355510 